\title{
Analytical investigation of a three-dimensional FRP-retrofitted reinforced concrete structure's behaviour under earthquake load effect in ANSYS program
}

\author{
F. Altun ${ }^{1}$ and F. Birdal ${ }^{2}$ \\ ${ }^{1}$ Assoc. Fatih ALTUN, Erciyes University, Engineering Faculty, Civil Engineering Department, \\ Kayseri, Turkey \\ ${ }^{2}$ Res. Asst., Furkan BİRDAL, Erciyes University, Engineering Faculty, Civil Engineering Department, \\ Kayseri, Turkey \\ Correspondence to: F. Altun (faltun@erciyes.edu.tr)
}

Received: 31 August 2012 - Accepted: 16 November 2012 - Published: 18 December 2012

\begin{abstract}
In this study, a 1:3 scaled, three-storey, FRP (Fiber Reinforced Polymer) retrofitted reinforced concrete model structure whose behaviour and crack development were identified experimentally in the laboratory was investigated analytically. Determination of structural behaviour under earthquake load is only possible in a laboratory environment with a specific scale, as carrying out structural experiments is difficult due to the evaluation of increased parameter numbers and because it requires an expensive laboratory setup. In an analytical study, structure was modelled using ANSYS Finite Element Package Program (2007), and its behaviour and crack development were revealed. When experimental difficulties are taken into consideration, analytical investigation of structure behaviour is more economic and much faster. At the end of the study, experimental results of structural behaviour and crack development were compared with analytical data. It was concluded that in a model structure retrofitted with FRP, the behaviour and cracking model can be determined without testing by determining the reasons for the points where analytical results are not converged with experimental data. Better understanding of structural behaviour is analytically enabled with the study.
\end{abstract}

\section{Introduction}

Earthquakes are a dynamic force affecting structures laterally. Under the earthquake effect, damages occur in structures when material durability is low and there is error of design. When the damages are destructive, it widely causes loss of life and property. This situation results in economic losses whose compensation is very hard for the national economy. Design of a structures as earthquake resistant prevents these losses. As for the present structures which are not earthquake resistant, their restoration and reinforcement are necessary. In order to determine the behaviour of earthquake effect on a structure, it is observed that there is an increase in the number of experiments in laboratory with developing technology. However, experimental studies are difficult and time consuming.

In this study, doing an analytical model of an experimental study was aimed. With this aim, experimental results of a three-dimensional model structure have been analyzed with finite element method. In experiments, joints of $1: 3$ scaled, three-storey and three-dimensional reinforced concrete structure are retrofitted with FRP (Fiber Reinforced Polymer). At the end of experimental results under lateral load, a forcedisplacement curve and crack developments of the sample were determined. Experimental results were compared with data obtained from the result of an analytical study.

Although there are lots of experimental studies regarding formation of reinforced structure pushover curves, analytical studies have remained on a limited scale. In recent years, employment of finite element method has become common with 
the development of computer technology. Especially in civil engineering, it is beginning to be used widely with regards to the predictions of reinforced concrete member and frame behaviours. The most accurate methods are being developed for concrete and reinforced concrete with finite element method.

ANSYS Finite Element Package Program (2007) makes modelling of composite elements easy. However, as all the data during modelling affects solution duration and process volume, these data need to be determined and described. For this reason, the concrete and rebar model program used, and the cracking hypothesis becomes important in order to reach the result with the least process volume by setting an accurate model in ANSYS package program (2007). Thus, after many experiments were carried out on different reinforced concrete models in the program, the analysis of the $1: 3$ scaled, three-dimensional reinforced concrete model structure was performed.

In this article, a $1: 3$ scaled test sample modelled with ANSYS package program (2007) was strengthened with carbon fibre reinforced polymer (Altun, 2010). ANSYS package program (2007) was preferred as it enables FRP modelling. In the program, SOLID 65 element type was used for concrete and SOLID 46 element type was used for FRP. When FRP was being modelled, first plate fields were composed, and then volumes were composed from these fields. After FRP plates were modelled, these plates were placed to joints in the structure. For this jointing, dimensions of reinforced concrete and FRP material of finite element were chosen in equal dimensions in order to provide overlap. The model consists of 188000 elements including FRP plates. Bonding of FRP plates to the concrete surface was provided by the GLUE instruction within ANSYS package program (2007). In order to eradicate the sample torsion effects in the experiments, steel frames were constructed for both sides of the model. This case was defined in ANSYS package program (2007) by assigning restraints to edges of both sides whose behaviours were prevented in $\mathrm{x}$-direction, but free in z-direction. Loading to the model was applied to $1: 3$ of the plate of between third and second storey. A steel plate whose thickness is $50 \mathrm{~mm}$ was modelled between last floor and the second floor. Load was applied to the model via this plate.

In literature, experimental and analytical investigation of element and scaled structure systems has been conducted. It is experimentally and analytically identified that reinforced concrete beams reinforced with FRP increase rigidity, durability and ultimately load capacity (Triantafillou, 1992; Hsuan-Teh, 2004; Chen, 2012; Norris, 1997). For instance, in the study carried out by Triantafillou and Plevris (1992), behaviours of beams strengthened with FRP were investigated analytically and experimentally. In the study, two cases were indicated as FRP rupture and debonding. In the article, an empirical formula related to FRP proportion was given. In the studies carried out on 8 beams, when FRP proportion calculated by the given empirical formula reached 0.0043 value, the failure mechanism of FRP passed from FRP rupture to debonding, and this was indicated in the form of a table. Hsuan-The Hu et al. (2004) carried out a study based on finite element method in order to identify the ultimate load capacity of rectangular beams strengthened with fiber reinforced plastics. They used long and short beams in the study. As a reinforcement method, they reinforced the beams on two sides and from the bottom. Consequently, it is emphasized that the behaviour of beams which have a high reinforcement ratio was not affected by the length of beam, but length of the beam was effective for beams which have a low reinforcement ratio. Moreover, it was stated that crack development changes depending on reinforcement ratio; the number of cracks and ultimate strength capacity in beams reinforced with FRP from both sides are less than reinforcement from the bottom.

It was identified that shear occurs on FRP material and analytical data durability was investigated during retrofit of reinforcement concrete beams. In the analytical evaluation made by modelling with ANSYS package program (2007), it was identified that FRP material can shear, and analytical data is consistent with experimental results (Elyasian, 2006).

In the study carried out on circular beams repaired with FRP, the effect of FRP plate thickness, direction and rigidity on behaviour was investigated analytically and experimentally. In analytical investigation, ANSYS package program (2007) was used; results were compared with experimental data and approximate values were obtained $(\mathrm{Li}$, 2003).

Retrofitting of joints with FRP was investigated by doing analysis in ANSYS package program (2007). In the study, an eight-storey frame was strengthened with steel braces and CFRP (Carbon Fiber Reinforced Polymer). In the article, initially they analysed interior and exterior joints strengthened with FRP by using finite element methods. And then, they made a nonlinear pushover analysis for frame. They mentioned that FRP plates increase lateral load capacity in strengthened frame up to $40 \%$. Furthermore, it was noted that performance level of the frame got better (Niroomandi, 2010).

In an another study where joints were reinforced with FRP, FRP material applied longitudinally and horizontally increased the value of occurring tension and shear stress. In the study, 3 column-beam joints were strengthened with FRP laminates in different lengths and various materials; in this way their effects on moment capacity were investigated. Eglass, carbon and Kevlar were used as FRP material. A joint was designed as a control sample, and in the other two samples FRP was applied. In the study, it was stated that binding in the form of wrap prevents debonding of FRP plates. It was also emphasized that binding method and FRP thickness affect the performance. It was observed that samples strengthened with FRP increase moment capacity up to $37 \%$ (Parvin, 2000).

The effect of FRP material on reinforcement was investigated in a full-scale structure. A semi-dynamic test was done 

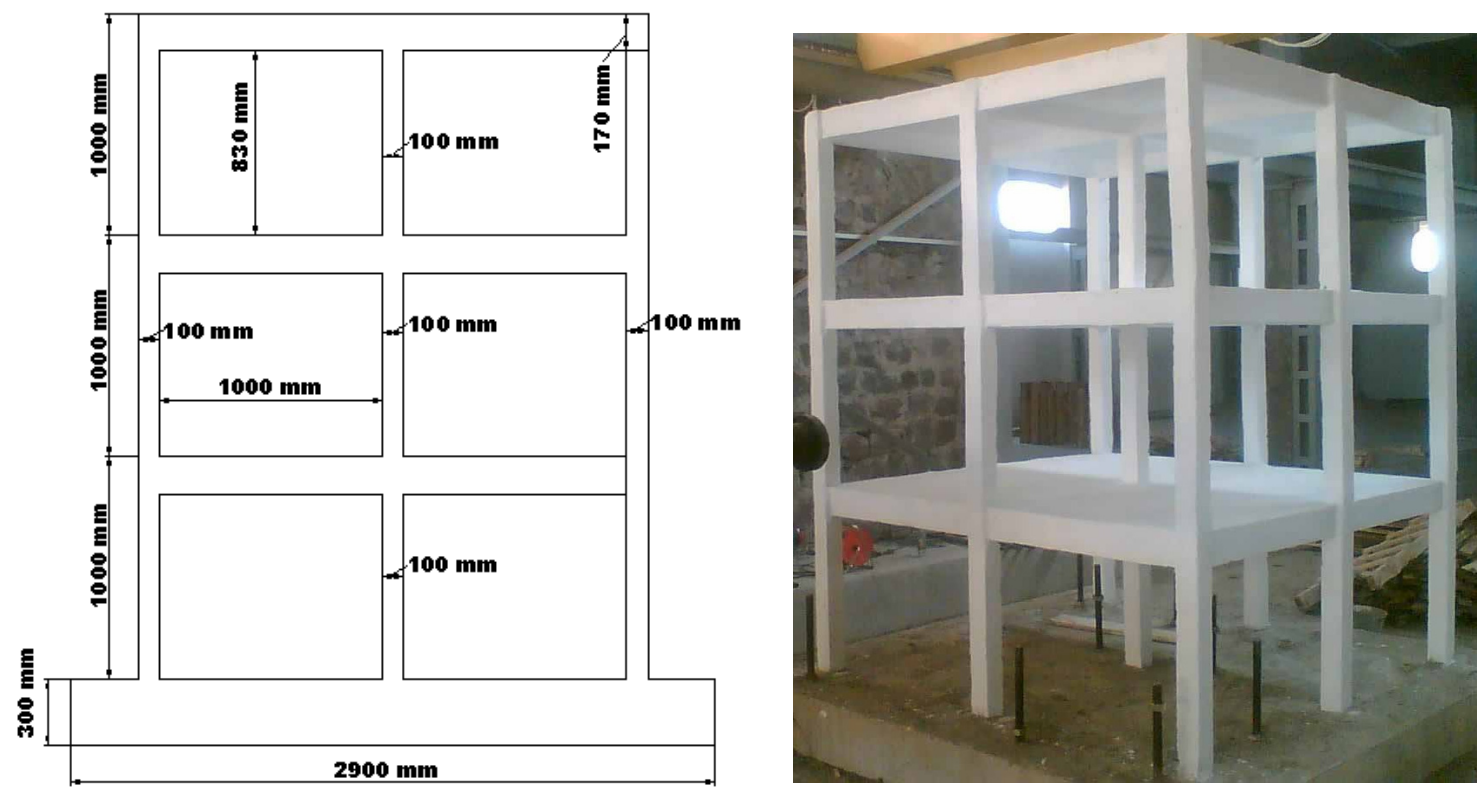

Fig. 1. Structure and dimensions of 3-D experimental model (Altun, 2010).

to the structure in laboratory and reinforced after it was exposed to damage at a certain level. Consequently, it showed a high displacement capacity without a great loss in the durability of the reinforced structure. Great damage was also not observed in reinforced elements (Balsamo, 2005).

In the Turkish Earthquake Code-2007, it is stated that application of fiber polymer to reinforced concrete increases shear and axial strength in columns. It is also emphasized that transformation of columns from rectangular shape to ellipses will increase the effect of fiber polymers. Moreover, the calculation basis is given in order that fiber polymers eradicate the deficiency of overlapping length in columns and effect of column ductility (TEC, 2007).

Studies in the literature centered on members due to the difficulty in conducting experiments. In this study, behaviour and crack development of a three-dimensional, three-storey, FRP retrofitted model structure whose earthquake behaviour was identified experimentally were stated analytically in ANSYS package program (2007).

\section{Analytically studied test specimen}

The test specimen whose model was formed using ANSYS package program (2007) is $1: 3$ scaled and threedimensional, with two bays and three stories. The test specimen was exposed to lateral load effect simulating earthquake loads. Tests were carried out in Erciyes University Earthquake Research Laboratory (Altun, 2010). The specimen was planned in a way that its concrete quality is low, there is not stirrup densification in the column-beam joint, and also there is not column stirrup as high as the beam in the column-beam joint and not adhesion to strong-columnweak-beam principle. Storey height of test specimen is given as $1000 \mathrm{~mm}$. Reinforced column cross section dimensions of specimen were chosen as $100 \mathrm{~mm} \times 100 \mathrm{~mm}$, its reinforced beam dimensions as $70 \mathrm{~mm} \times 170 \mathrm{~mm}$, its slab thickness as $40 \mathrm{~mm}$ and concrete cover values as $5 \mathrm{~mm}$. Longitudinal bar diameter in columns was used as $\phi 6$, confinement bar as $\phi 4$. Lateral earthquake load effect was applied to specimen by means of a supported hydraulic jack against a rigid wall. Raft foundation was chosen in order to satisfy encastre supported conditions (Altun, 2010).

Tests were done in two phases. In the first phase, the specimen was tested without reinforcement and damaged in a way that reached collapse prevention damage level. In the second phase, the damaged structure was reinforced with FRP. Reinforcement with FRP was realized in column-beam joints. FRP reinforcement of the test sample, whose analytical model was designed in this article, started with the repair of joints by using repair mortar in experiments. Columnbeam joints of the damaged sample were repaired by pouring concrete cover. In the course of repair work, cracks occurring in joints were repaired by applying pressurized epoxy. After a repair was done, the column cross section sides were made ready for FRP application by rounding. After this process, FRP plates were prepared and applied to confinement zones of the columns and beams. Application was made with a special mixture in the form of bonding (Altun, 2010). FRP wrapping was done separately in side and middle joint points. The fiber polymer reinforced state of the test specimen before damage and after damage is given in Figs. 1 and 2.

In the reinforced and non-reinforced trail, tests were done by putting $24 \mathrm{kN}$ of steady load on the first and second 


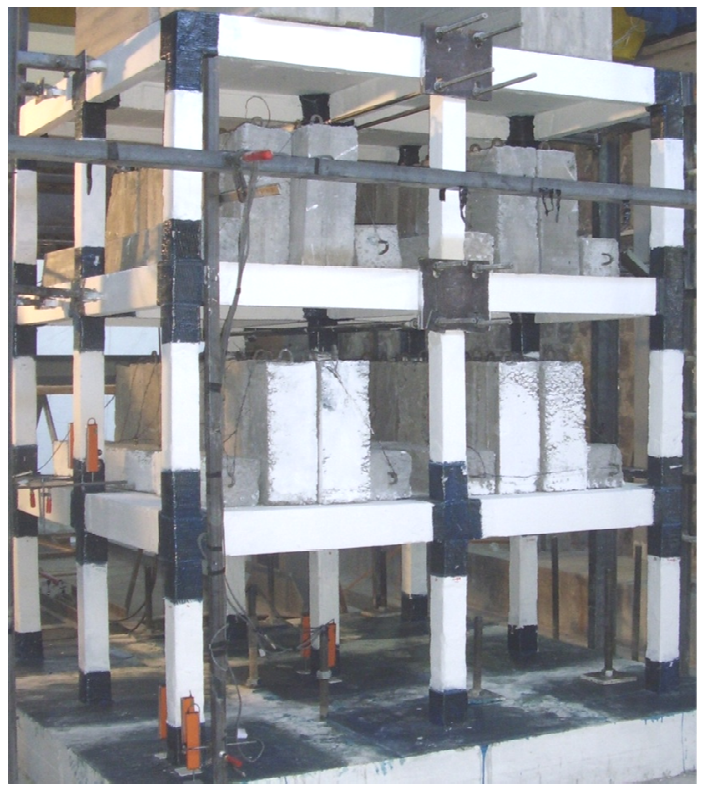

Fig. 2. Retrofitted experimental model structure (Altun, 2010).

stories, and $27.7 \mathrm{kN}$ on the third storey in a way that represents actual structure weight. These load values were taken into consideration while modelling in ANSYS package program (2007).

\section{Analytical study}

There are various steps to making a system model in ANSYS package program (2007). A finite element model composed of joints and elements based on joints is achieved by forming joints first and then elements. In ANSYS package program (2007), there are phases for drawing model, defining material features, choosing type of element, entering constants belonging to elements, performing mesh procedure and loading the model. The three-dimensional view formed with ANSYS package program (2007) of the model that was reinforced with FRP is given in Fig. 3 (Birdal, 2010).

While modelling reinforced concrete, SOLID 65 volumetric element having 8 joints was used in the program. There are three degrees of freedom in each joint of this element. The element has features such as leading to plastic deformation, cracking and crushing.

The SOLID 46 element was used while modelling FRP material. This element type used in modelling layered material is three-dimensional and has 8 joints. It enables definition of 250 layers having various angles and thicknesses. In the study, FRP materials used in the model have two layers.

In our model, load plates were defined in order to prevent local stress concentration on load application points (Chansawat, 2001). SOLID 45 was used for these plates. While material features of SOLID 65 concrete model were being entered in the study, the definition for wrapped and

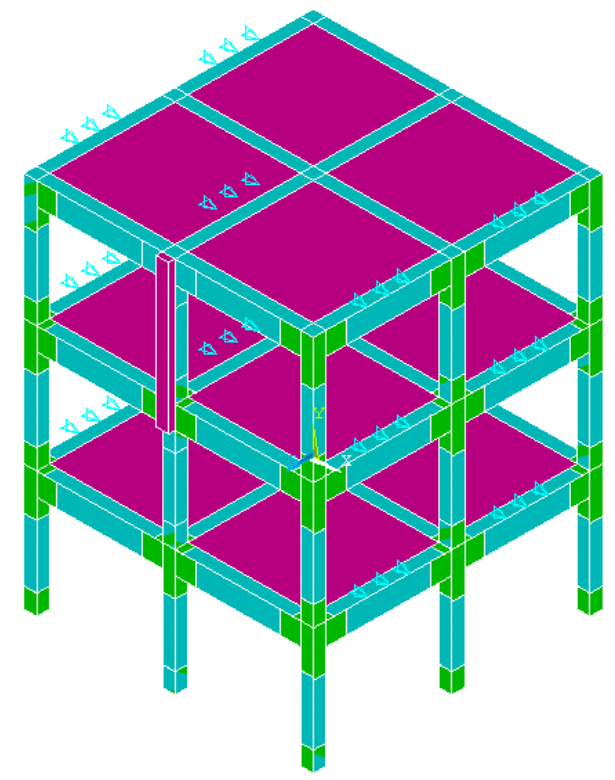

Fig. 3. Finite element model of retrofitted test specimen.

unwrapped concrete models was given by calculating stressstrain curves. In nonlinear inelastic data for concrete material, four values were given as shear transfer parameter for closed cracks, shear transfer parameter for opened cracks, unidirectional tensile strength and unidirectional compressive strength. Elastic modulus of the concrete was used as $13248 \mathrm{MPa}$ for initial slope of stress-strain curve.

In literature, the element type of FRP material was modelled as SOLID 46 in analytical studies carried out on elements and structures reinforced with FRP (Chansawat, 2001; Dogan, 2008). Two layers were defined as SOLID 46 material element constants. SOLID 45 material was used for steel. Elastic modulus of the steel was chosen as $2.1 \times 10^{5} \mathrm{~N} \mathrm{~mm}^{-2}$ and poisson rate as 0.3 . In our model, constants defined as Set 1, Set 2, Set 3 and Set 4 consist of rebar definitions. In the reinforced concrete model used in ANSYS package program (2007), it was assumed that rebar was scattered throughout the elements. For this reason, real constants were entered for SOLID 65 model. Set 1 is concrete rate without rebar, Set 2 is column longitudinal reinforcement rate, Set 3 is beam longitudinal reinforcement rate, and Set 4 is rebar rate at intersections of beam and column longitudinal reinforcements. The general view of material features at the end of the definition is given in Fig. 4.

Structure model was separated into $20 \times 20 \times 20 \mathrm{~mm}$ sized mesh elements by taking rebar locations at intersections into consideration. As a result of this separation, the model that is not reinforced with FRP consists of 171419 pieces SOLID 65 elements and 15000 pieces SOLID 45 elements. The general view of the model that is reinforced with FRP is given in Fig. 5, separated into finite elements. 


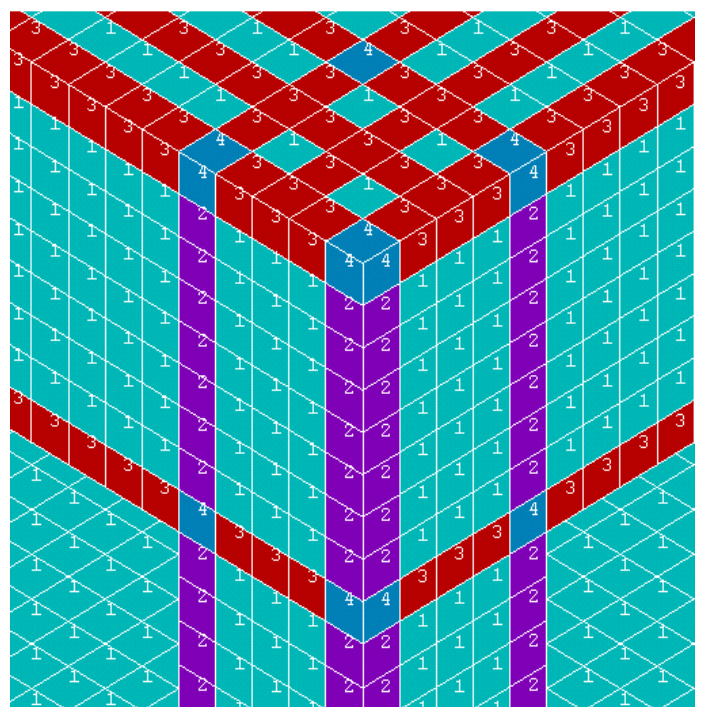

Fig. 4. Defining material properties on joints.

Usage of FRP material for reinforcement has become more common in recent years. Fiber polymer reinforcement systems increase durability and elasticity of reinforced concrete, steel, load-bearing tile and wooden elements against deflection, shear effect, longitudinal load and beats. Fiber polymers have very high tensile strength and modulus of elasticity. The retrofitting procedure continues while structural and industrial sites provide service without evacuating the structure. In addition, these materials are very light. Values of $2.4 \times 10^{5} \mathrm{~N} \mathrm{~mm}^{-2}$ for modulus of elasticity, $3.8 \times 10^{3} \mathrm{~N} \mathrm{~mm}^{-2}$ for tensile strength, $0.117 \mathrm{~mm}$ for designing section thickness, $230 \mathrm{~g} \mathrm{~m}^{-2}$ for total weight, $1.55 \%$ for strain failure and $300 / 600 \mathrm{~mm}$ for dimension were used for FRP material in the retrofitted model in the study (Norris, 1997; BASF Structural Chemicals Guide, 2008).

Design principles of the structure retrofitted with fiber polymers are identified by taking conventional design principles and mechanical features of fiber polymers into consideration. ANSYS package program (2007) was preferred as it enables doing FRP modelling on concrete. When FRP was being modelled, first members were formed, and then areas were modelled and volumes were composed. FRP plates were glued on concrete surfaces with GLUE instruction in the ANSYS package program (2007). FRP plates were separated into mesh elements in the same element sizes as column and beams. Wrapping details of FRP plates in corner, side and middle joint points are given in Fig. 6.

First, FRP plane plates were modelled while defining FRP material. These plates on $x-y$ and $y-z$ planes were composed according to the model on side and corner columns. The model of FRP layers is given in Fig. 7. After FRP plates were modelled, these plates were attached to joint points in the structure. For this attachment, finite element dimensions of FRP and reinforced concrete sections were chosen equally

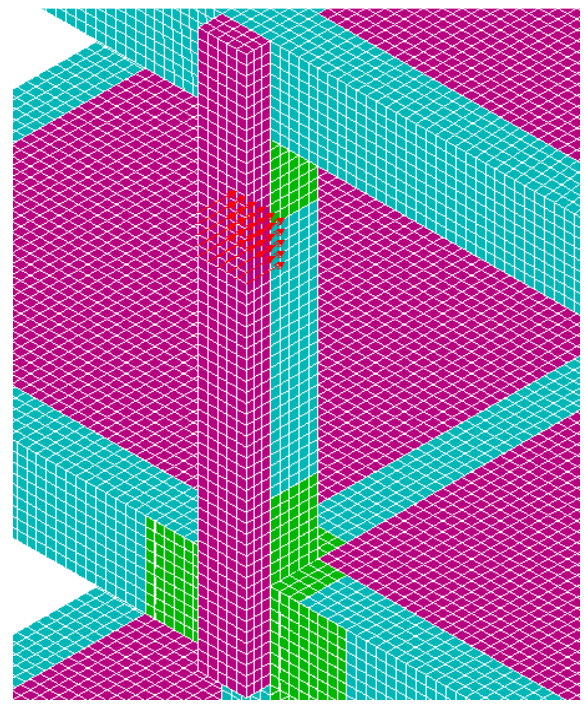

Fig. 5. Finite element model of structure and load plate.
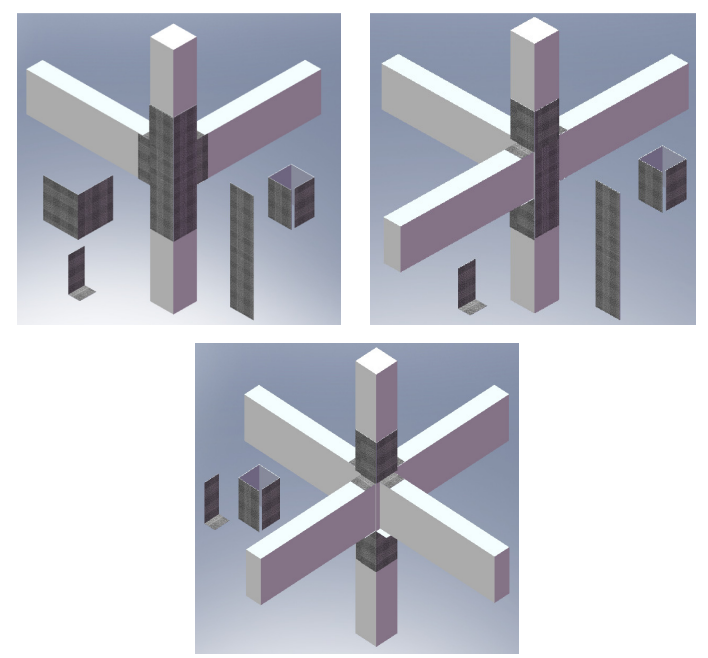

Fig. 6. FRP application details of corner, side and middle joints.

in order to provide full overlap. Views of analytical and experimental FRP fixed joints are given in Fig. 8.

In order to prevent torsional effect in the test specimen, steel frames were constructed on both sides of the specimen. This situation was defined by using restraints whose movements were prevented in the $\mathrm{x}$-axial direction but set free in the $\mathrm{z}$-axial direction.

In ANSYS package program (2007), loadings can be applied by using time-load history. In an analysis, there may be more than one load step. In every load step, loading was realized with certain increasing steps beginning from the initial value of the load. Time-dependent steps can be given as time increments or number of sub-steps (Dede, 2006). When giving time-dependent load increments, values of maximum and minimum time steps were entered to the program. 


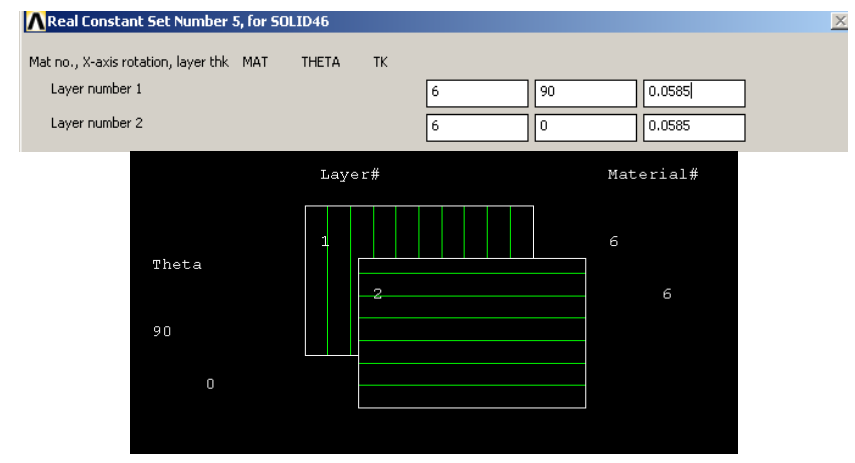

Fig. 7. Model of FRP layers.

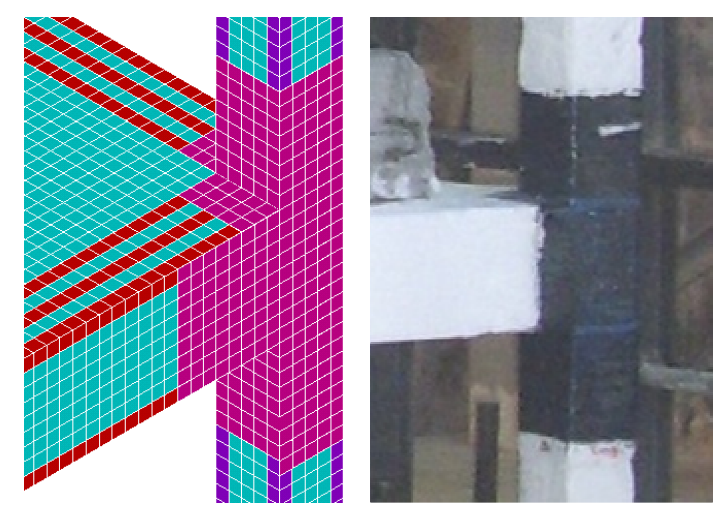

Fig. 8. Experimental and analytical views of FRP application.

\section{Analytical result and discussion}

In the analysis of reinforced concrete model, $300 \mathrm{~N}$ load was applied to every node as the initial load step. This accounts for $9000 \mathrm{~N}$ load effect for the structure in total. Towards the end of the analysis, an increasing step was defined as $0.5 \mathrm{~N}$, minimum increasing step as $0.1 \mathrm{~N}$, and maximum increasing step as $1 \mathrm{~N}$. When analysis started, maximum iteration number was adjusted to 40 because generally in literature the default iteration number (25) was exceeded in different analyses. This means that analysis can converge beyond the default iteration number.

Experimental and analytical results of peak point forcedisplacement curve of the FRP retrofitted three-storey model were given in Fig. 9, and the relationship of storey forcedisplacement for each storey is also given in Fig. 10.

The experimental curve is an envelope curve in the pushing direction of the hysteresis curve, being a push-pull curve applied to the specimen.

In analytical study, it was seen that the slope of the forcedisplacement curve proceeded more steeply. As this situation may result from the defects in the test specimen concrete, it is thought that it can also be a result of the FRP plates attached to the joints.

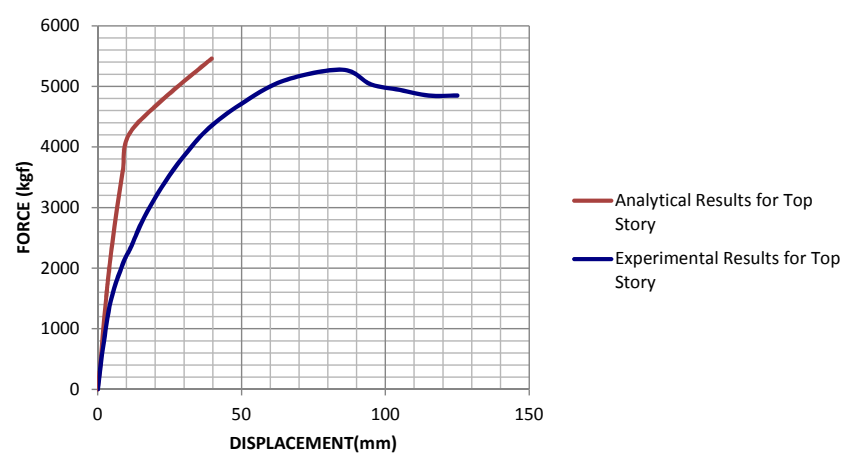

Fig. 9. Retrofitted specimen experimental and analytical forcedisplacement curve for top storey.

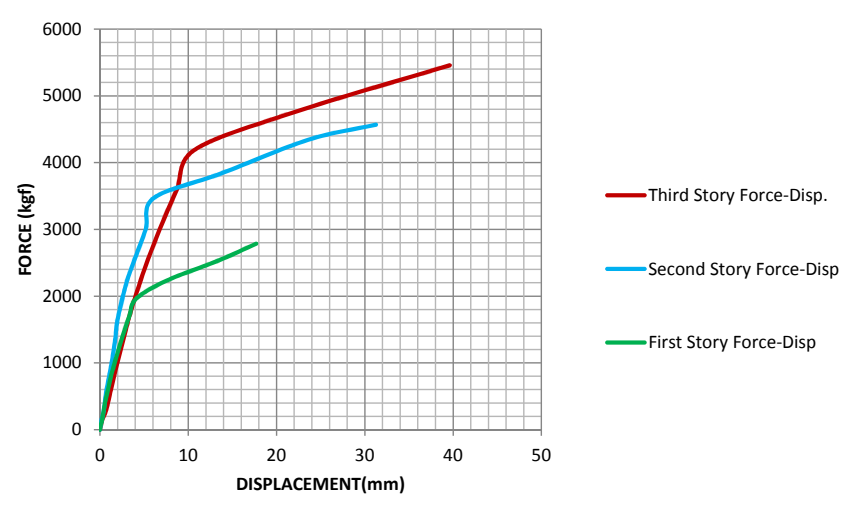

Fig. 10. Storey force-displacement relationship for each storey.

In analysis carried out with ANSYS package program (2007), it is easy to obtain the linear area of loaddisplacement curve. Obtaining nonlinear area can be possible up to a certain value. However, providing the continuation of behaviour in the nonlinear area can be possible by increasing the step number and supplementing additional iterations. Analysis converged after a certain value. It was found out that the shear transfer parameter defined while modelling is important for closed cracks; shear transfer parameter is also important for open cracks regarding the convergence of analysis. Defining load application restraint to the point load applied enables the analysis to converge easier. In the study, an analysis with 188000 finite elements was performed, and loading was done with a certain number of load steps.

Crack developments in loading steps and their forms were identified during analysis. Analytically, crack developments of retrofitted specimen in a damage situation is given in Fig. 11 for three-dimensional and single axes. It was also found that experimental data is consistent with crack development at the end of the analytical solution in the loading step. 

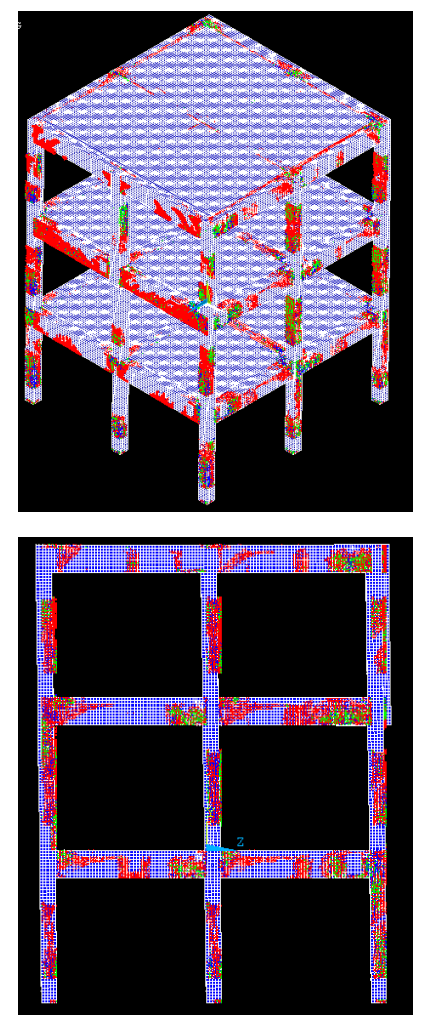

Fig. 11. Analytical crack development.

\section{Summary and conclusions}

In the study, experimental behaviour of a three-storey, threedimensional and $1: 3$ scaled structure retrofitted with FRP was investigated analytically. Crack development and experimental force-displacement behaviour obtained for the model structure were identified analytically. In analytical studies, ANSYS package program (2007) was used. Analytical results of behaviour and crack development were compared with experimental data, and consistency of the analytical study and experimental data was investigated. In the analysis carried out with ANSYS package program (2007), it was observed that slope of the force-displacement curve proceeded more steeply. Reasons of this situation are that the actual specimen was more defective, the test specimen was retrofitted after suffering preliminary damage, and FRPs on the surface of some members peeled during the test while FRP plates were attached to the model surface at all points. At the end of the study, the behaviour and cracking model that would occur were identified analytically in a model structure retrofitted with FRP without testing. An analytically significant contribution was made to better understanding this result behaviour.
Acknowledgements. This study was supported financially by Research Fund of Erciyes University BAP (Project no.: FBY-09-826).

Edited by: M. E. Contadakis

Reviewed by: two anonymous referees

\section{References}

Altun, F.: Experimental Investigation Project of Fiber Polymer Application for Retrofitting Reinforced Concrete Buildings Against Eartkquake, Project No: FBA-08-477 Research Fund of Erciyes University, 2010.

Ansys Finite Element Package Program Help Menu version 11, 2007.

Balsamo, A., Colombo, A., Manfredi, G., Negro, P., and Prota, A.: Seismic Behaviour of a Full-Scale RC Frame Repaired Using CFRP Laminates, Engineering Structures, 27, 769-780, 2005.

Birdal, F.: Analysis of Strengthened 3-D Reinforced Concrete Structure Model With Pushover Method, M. S. Thesis, Erciyes University, Kayseri, 2010.

Chansawat, K., Kachlakev, D., and Miller, T. H.: FE Modelling and Experimental Verification of an FRP Strengthened Bridge, Technical Report, Oregon State University, Oregon, USA, 2001.

Chen G., M., Chen, J. F., and Teng, J. G.: On the Finite Element Modelling of RC Beams Shear-Strengthened with FRP, Constr. Build. Mater.,32, 13-26, 2012.

Dede, F. T.: Nonlinear Finite Element analysis of Reinforced Concrete Frames Subjected to Reversed-Cyclic Loading Using ANSYS Software, M. S. Thesis, Selcuk University, Konya, 2006.

Dogan, A. B.: Non Lineer Finite Element Analysis of Concrete Beams Strengthened with Carbon Fiber Reinforced Plastics, M. S. Thesis, Gazi University, Ankara, 2008.

Elyasian, I., Abdoli, N., and Ronagh, H. R.: Evaluation of Parameters Effective in FRP Shear Strengthening of RC Beams Using FE Method, Asian Journal Of Civil Engineering (Building And Housing), 7, 249-257, 2006.

Fiber Ploymers (FRP): Retrofitting Systems, BASF Structural Chemicals Guide, BASF Structural Chemicals Company, Istanbul, 3-11, 2008.

Hsuan-Teh, H., Fu-Ming, L., and Yih-Yuan, J.: Nonlinear Finite Element Analysis of Reinforced Concrete Beams Strengthened by Fiber-Reinforced Plastics, Compos. Struct., 63, 271-281, 2004.

Li, G., Kidane, S., Pang, S. S., Helms, J. E., and Stubblefield, M. A.: Investigation into FRP Repaired RC Columns, Compos. Struct., 62, 83-89, 2003.

Niroomandi, A., Maheri, A., Maheri Mahmoud, R., and Mahini, S. S.: Seismic Performance of Ordinary RC Frames Retrofitted at Joints by FRP Sheets, Eng. Struct., 32, 2326-2336, 2010.

Norris, T., Saadatmanesh, H., and Ehsani, M. R.: Shear and Flexural Strengthening of R/C Beams with Carbon Fiber Sheets, J. Struct. Eng.-ASCE, 123, 903-911, 1997.

Parvin, A. and Granata, P.: Investigation On The Effects of Fiber Composites at Concrete Joints, Composites, part B, 31, 499-509, 2000.

TEC-2007: Turkish Earthquake (Seismic) Code, Regulations on structures constructed in disaster regions, Ministry of Public Works And Settlement, Ankara, 2007.

Triantafillou T. C. and Plevris, N.: Strengthening of RC Beams with Epoxy Bonded Fibre Composite Materials, Mater. Struct., 25, 201-211, 1992. 